\title{
Employment Effects of International Factor Mobility : A Theoretical Approach with Heterogenous Labor
}

\author{
Thomas Gries and Stefan Jungblut \\ University of Paderborn
}

\begin{abstract}
In many countries the difference in labor market performance for skilled and unskilled workers has increased over the past decades. While an extended literature exists on the employment effects of trade, less is known about the effects of factor mobility. Based on the "labor market flow approach", we develop a model of persistent structural unemployment for skilled and unskilled workers. Within this model the effects of capital mobility and migration are analyzed. Given that real and human capital are complements we find that skilled and unskilled worker will both gain from capital inflows. Within each labor market segment, the effects of labor inflows is always negative. The cross effects of labor infows, however, are non-symmetrical: On the one hand, an inflow of unskilled labor negatively affects the unskilled segment, but will not affect the unemployment rate of skilled workers. On the other hand, an inflow of skilled labor will always negatively affect the unemployment rate in both segments of the labor market. If policy makers would like to avoid these effect, the number of unskilled must simultaneously be decreased, the rate of internal real capital accumulation must be increased or real and human capital must be imported as a bundle.
\end{abstract}

- JEL classification: F15, F21, O15, J21

- Keywords: International factor mobility, Unemployment, Human capital, Technological progress

\footnotetext{
*Corresponding address: Thomas Gries and Stefan Jungblut, Department of Economics, University of Paderborn, 33098 Paderborn, Germany. E-mail: thomas.gries@notes.uni-paderborn.de, jungbluit@notes.ipb.de, Tel: +495251 602113, Fax: +495251603540 


\section{Introduction}

The effects of international integration to labor markets are discussed in various dimensions. In the recent wage inequality debate ${ }^{1}$ increasing globalization is considered as an important factor. Hence a number of contributions analyze the effects of international integration and trade liberalization on labor market performance. ${ }^{2}$ One important proposition in this debate is a negative impact from trade liberalization on unskilled labor. Wood (1998) concludes "... I review and reappraise the evidence, suggesting that most of it is, in fact, consistent with the hypothesis that the main cause of the rise in labor market inequalities is globalization." [Wood (1998, p. 1468)]. While the majority of authors focus on trade, the impact of globalization on domestic labor markets goes well beyond its linkage with trade. A second channel is opened through factor mobility. Factor mobility also has been increasing substantially. Between the early 1960s and 2000 world trade increased by a factor of about $50 .{ }^{3}$ In the same period only FDI as a small fraction of total capital mobility expanded by a similar factor. ${ }^{4}$ Even migration of labor rose by a factor of $1.6^{5}$ in the period 1965 to 1990 . While trade in goods and services affects labor markets more indirectly, migration and capital mobility directly affect factor markets and relative factor prices. Therefore, both capital mobility and labor migration must be expected to play a major role for labor markets. ${ }^{6}$

In the public debate, labor immigration is often suspected of exacerbating labor

\footnotetext{
${ }^{1}$ While increasing wage inequality is an important problem in the US [see e.g. OECD (1997), Gottschalk/ Smeeding (1997), Murphy/Topel (1997)], in many European economies high unemployment rates especially among low skilled workers are at the centre of the debate. In fact different segments of the labor market show a highly different development. In Europe, the probability of unemployment has increased far more for low skilled labor than for high skilled workers.

${ }^{2}$ The main focus of these studies is the contribution of trade to the observed increase in the wage gap between skilled and unskilled labor. See e.g. Wood (1994, 1995, 1997, 1998, 2002), Sachs/Shatz (1996), Pizer (2000), Krugman (2000) or Glazer/Ranjan (2003).

${ }^{3}$ See WTO (2005).

${ }^{4}$ UNCTAD (2005).

${ }^{5}$ Stalker (2000), table 1.1, p7.

${ }^{6}$ Borjas/Freeman/Katz (1996) conclude: "Our factor proportions estimates of the effect of migration and trade show that immigration contributed more to the decline in relative earnings of high school drop outs than trade." Borjas/Freeman/Katz (1996) p.246.
} 
market problems. Immigrants are blamed for displacing domestic workers. While there is little controversy about the effect of immigration on the own labor market segment, the debate about cross effects is still open. Will an inflow of skilled workers reduce or raise the unemployment rate among unskilled workers? Does immigration of unskilled workers worsen unemployment among skilled workers as well?

A similar ambiguity arises with respect to capital markets. Does capital market integration affect the unemployment rate of the skilled or unskilled, or both? Generally, one would expect that inflowing capital and FDI will have a positive effect on employment. However, even if this optimistic view might be appropriate for the aggregate, it is far from clear whether all segments of the labor market will gain equally. What happens if the inflowing capital only matches with skilled labor? Will there still be a positive effect on unskilled labor? As Hanson* (1995) points out, "... the possibility must be considered that international labor market, ..., operated in such a way as to match machinery and equipment with skill, not only with the least expensive labor that could be found." [Hanson II (1995 p.156)]. Although there are several contributions to the discussion of employment effects of capital mobility with respect to $\mathrm{FDI}^{7}$ and outsourcing ${ }^{8}$, up to now no consensus has been reached about the structural effects on different labor market segments. Further, looking at the rather specific factor relations in real production processes, cross employment effects of inflowing labor and capital are not really understood for both labor market segments.

While most of the contributions of the debate above focus on the empirical side and/or specific phenomena e.g. FDI, the idea of this paper is to systematically analyze the unemployment effects of international factor mobility on different segments of the labor market in a more general theoretical approach. The model attempts to pay particular attention to specific labor market conditions. As pointed out by the OECD: “...The net outcome on employment depends on the nature of technological advance, the degree of substitution between inputs, the degree of labor market flexibility and mechanisms of upgrading labor skills, and the role of institutions... The failure of equilibrating mechanisms to work adequately can be traced to skill mismatches, labor market rigidities, and to problems in the

\footnotetext{
${ }^{7}$ See e.g. Koizumi/Kopecky (1980), Lall (1995), Slaughter/Swagel (1997) or Glass/Saggi (1999), Baldwin/ Venables (1994).

${ }^{8}$ See e.g. Feenstra/Hanson (1996), Lawrence (1994) or Slauther (1995).
} 
institutional and regulatory structure of economies." (OECD (1998 p.49)). To be able to address the specific problems mentioned by the OECD, like "mismatch, ... rigidities and institutional problems", we take the matching approach to labor markets as a starting point. ${ }^{9}$ Using the matching approach it is possible to address information and transaction cost as well as the institutional framework. Therefore, this approach is more flexible than the basic neoclassical labor market model, which is included as a special case.

The model explicitly distinguishes between different skill groups, termed skilled and unskilled workers. In addition, a third factor of production is real capital, which embodies production technology. As pointed out in an OECD (1998) survey, these three factors are employed in a rather specific combination. In the model, the stylized characteristics of factor relations are captured by a nested CES production function for the final good. For this factor relations equilibrium unemployment is determined.

After deriving the long-term unemployment equilibrium for each segment of the labor market, international factor mobility is introduced and the effects of capital and labor inflows on relative factor prices and employment rates are analyzed. The main findings of the analysis are:

1) Skilled and unskilled labor will always gain/lose from capital inflows/ outflows. Due to the capital skill complementarity assumption applied in the model, an inflow of real capital will increase the real capital stock and in turn increase employment opportunities. Moreover, since interest rates are costs in the firms' investments in recruitment, lower interest rates will raise search efforts in both labor market segments. Higher investments in personnel search activities increase the probability of finding an appropriate worker for a vacancy. With a rise in the speed of filling vacancies unemployment rates will decrease.

2) Inflows of any kind of labor will always adversely affect the own labor market segment. Migration generally increases the labor supply and, with constant investments in personnel search activities, increases unemployment in the affected labor market segment.

3) The cross effects of immigration are non-symmetrical: (a) The inflow of unskilled labor has no effect on the skilled labor market segment. The equilibrium unemployment rate of skilled labor is immune with respect to the immigration of

\footnotetext{
${ }^{9}$ The matching approach to the labor market goes back to Pissarides (1979, 1985, 2000), Mortensen (1978, 1986, 1989), Diamond/Maskin (1979), Diamond (1982), Howitt (1985) or Blanchard/Diamond (1992).
} 
unskilled labor. (b) The inflow of skilled labor will affect unskilled and skilled segments negatively.

\section{The Model}

This section introduces an open economy labor market matching model. In a labor market flow-matching model there is a continuous separation of existing jobs. Separations plus workforce growth indicate the inflow into the labor market. Conversely firms offer vacancies for newly created or existing but vacant jobs. The number of vacancies offered by firms depends on the cost of employment as well as the cost of job creation or reemployment. The probability of matching a job profile with a worker's skill and ability profile determines the flow of unemployed workers out of the labor market into employment. The matching function covers mismatch as well as rigidities and institutional characteristics. The separation rate plus the population growth rate minus the job-matching rate results in the net change in unemployment. If inflow equals outflow the labor market is in a flow equilibrium, i.e. has a constant unemployment rate.

The formal model is developed in three steps. First, the labor market equilibrium is characterized. In a second step, the optimal search activities of firms are derived. Finally, factor income and factor accumulation are introduced.

\section{A. Labor Market}

\section{Workers}

We consider an economy with a large number of households. The aggregate labor endowment of households, $\bar{L}$, is constant. There are two types of workers, skilled and unskilled. The unskilled workers, $L_{u}$, offer unskilled labor services while the skilled workers, $L_{s}$, offer human capital services. The aggregate share of both types of workers is constant.

At any point in time workers of each type are either employed, or unemployed and searching for a job. The number of employed and unemployed workers is denoted $N_{j}$ and $U_{j}$ respectively, with

$$
N_{j}+U_{j}=L_{j}, \quad j=u, s
$$

\section{Matching Problem}

Labor market activities are described by search activities of workers, and job 
creation and reemployment activities of firms. The search activity of workers is indicated by the number of unemployed in each segment of the labor market, $U_{u}$ and $U_{s}$, while job creation and reemployment activities of firms are measured by the number of vacancies offered for each type of worker, $V_{u}$ and $V_{s}$. The number of successful job matches, $M_{j}$, is a function of search activities and vacancies:

$$
M_{j}=M_{j}\left(U_{j}, V_{j}\right), j=u, s
$$

We assume that the matching technology $M_{j}(\cdot)$ is linear homogenous. ${ }^{10}$ Thus, the probability to filling a vacancy, $q$, as well as the probability of finding a job, $p$, is a function of the ratio of $V_{j}$ to $U_{j}$ only. These probabilities are given by

$$
\begin{aligned}
& \frac{M_{j}}{V_{j}}=M_{j}\left(U_{j} / V_{j}, 1\right)=: q\left(\theta_{j}\right) \text {, with } \partial q\left(\theta_{j}\right) / \partial \theta_{j}<0 \\
& \frac{M_{j}}{U_{j}}=M_{j}\left(1, V_{j} / U_{j}\right)=: p\left(\theta_{j}\right), \text { with } \partial p\left(\theta_{j}\right) / \partial \theta_{j}>0
\end{aligned}
$$

where

$$
\theta_{j} \equiv V_{j} / U_{j}
$$

indicates the tightness of labor market segment $j=u, s$.

\section{Wage Rule}

Within the discussion of the matching approach the modeLing of a specific wage setting process is an important aspect. Wages are determined as the outcome of a bargaining process between firms and workers. ${ }^{11}$ In this paper we would like to keep the wage setting process as simple as possible. We propose a simple wage setting rule and assume that the wage rate, $w_{j}$, grows proportionately (with factor $\omega)$ to the marginal productivity of labor, $F_{N j}=\partial F / \partial N_{j}{ }^{12}$

\footnotetext{
${ }^{10}$ There is empirical evidence that the assumption of a linear homogeneous matching function is reasonable (See Pissarides (2000, p.35) and the references therein, and Petrongolo/Pissarides (2001)). Nevertheless, Diamond (1982), Howitt (1985), and Mortensen (1989) allow for increasing returns and obtain more interesting results including multiple equilibria and coordination failures. With respect to the purpose of this paper the assumption of a linear homogeneous matching function is a better choice.

${ }^{11}$ See e.g. Mortensen (1978), Diamond/Maskin (1979), Diamond (1982), Pissarides (1985, 2000).

${ }^{12}$ The functional from of the prooliction function $\mathrm{X}_{\mathrm{j}}=\mathrm{F}_{\mathrm{j}}(\ldots)$ in inhrodiced below.
} 


$$
w_{j}=\omega F_{N j} 0<\omega<1 .
$$

As $\omega$ gives the share of productivity growth distributed to labor, it may be understood as the result of the bargaining process mentioned but not modelled explicitly.

\section{Employment and Labor Market Flow Equilibrium}

While the standard model of the labor market is static with respect to presently employed workers, the labor market flow approach more realistically assumes a permanent process of job separation and job creation or reemployment. For all sort of reasons, firms lay off workers or workers leave their present job (separation). At the same time, firms hire new workers who meat the defined job conditions. The matching function (2) describes the outflow out of labor market $j=u, s$. The inflow into labor market $j$ is given by the number of jobs which are separated at any point in time. For simplicity, the separation rate, $\sigma_{j}$, is assumed to be given and constant. Thus, a change of employment, $\dot{N}_{j}$, is

$$
\dot{N}_{j}=M_{j}-\sigma_{j} N_{j}=V_{j} q\left(\theta_{j}\right)-\sigma_{j} N_{j}
$$

The labor market is in a flow equilibrium if inflow equals outflow:

$$
\dot{N}_{j}=0 \Leftrightarrow V_{j} q\left(\theta_{j}\right)=\sigma_{j} N_{j}
$$

The equilibrium unemployment rate $v_{j}$ in each segment is determined exclusively by labor market tightness ${ }^{13}$

$$
\mathrm{v}_{j}=\frac{U_{j}}{L_{j}}=\frac{1}{1+\theta_{j} q\left(\theta_{j}\right) / \sigma_{j}}, \text { with } \frac{d v_{j}}{d \theta_{j}}<0 .
$$

\section{B. Firms}

\section{General Production Process}

We start with a rather generalized description of the production process. The homogenous good produced by a single, representative firm $i$ is denoted $X^{i}$. The production function is a nested CES function with unskilled labor services, $\mathbf{L}$, and 
capital services, $\mathbf{K}$, as upper level inputs

$$
X^{i}=F\left(\mathbf{L}^{i}, \mathbf{K}^{i}\right):=\left[\mathbf{B}_{L}\left(L^{i}\right)^{-\gamma}+\mathbf{B}_{K}\left(k^{i}\right)^{-\gamma}\right]^{-\frac{1}{r}}
$$

Capital service $\mathbf{K}^{\mathrm{i}}$ is produced using real capital $K^{i}$ and human capital services, $H^{i}$. Goldin/Katz (1998) have justified this kind of production function by two dimensions in the production process: machine maintenance and assembly. In the first dimension, skilled workers adopt new technologies and ensure that they work efficiently in the organization. In the second dimension unskilled labor uses the equipment in a fully preorganized and prepared assembly process.

\section{Specification of Factor Services and Factor Relations}

As summarized by the OECD survey (1998), the following three inputs of production are in rather specific relations:

Unskilled labor: In the model, technological progress is unskilled labor augmenting, that is, in standardized production processes less skilled labor can be easily substituted by new technologies. ${ }^{14}$ As Acemoglu (2000, p.22) states, “...advances in equipment often appear to substitute machines for tasks previously performed by unskilled workers." The labor augmenting effect of technological progress is captured by defining an unskilled labor service measured in efficiency units, $\mathbf{L} \equiv \lambda N_{u}$, where $\lambda$ denotes a productivity parameter with a given constant growth rate $\hat{\lambda}$.

Human capital, real capital and capital services: Human capital input, $H^{i}$, is measured as the number of skilled workers presently employed $\left(N_{s}\right)$ times the per capita human capital endowment, $h: H^{i} \equiv h N_{s}^{i}$. Thus, in this growth model productivity growth of high skilled workers is driven by skill accumulation. ${ }^{15}$ The technology is embodied in real capital. Investing in real capital equipment is an investment in the embodied technology of the machine. Additional machines require skills and human capital for operation and maintenance. Therefore, the aggregate capital service is "produced" with real capital $K^{i}$ and human capital

\footnotetext{
${ }^{14}$ For example, automation in industry substitutes for low skill labor assembling a product, but not for engineers or process managers. A new electronic data processing technology in an insurance company substitutes for low skilled workers carrying and storing physical files. The electronic processing technology does not substitute for the skilled clerk who uses the files to provide customer services.

${ }^{15}$ This depiction of human capital is consistent with findings by e.g. Krueger (1993), DiNardo/Pischke (1997), or Entorf/Kramarz (1998) that with respect to information technologies the wage premium for high skilled labor is likely to be a premium for (unobservable) skills.
} 
service $H^{i}$.

The production of capital services $\mathbf{K}$ is also described by a CES function:

$$
\mathbf{K}^{i}:=\left(\left(K^{i}\right)^{-\mu}+\left(H^{i}\right)^{-\mu}\right)^{-\frac{1}{\mu}} \text {. Total production specified as }
$$

$$
\mathbf{K}^{i}:=\left[\mathbf{B}_{L}\left(\mathrm{~L}^{i}\right)^{-\gamma}+\beta_{\mathrm{K}}\left(\left(K^{i}\right)^{-\mu}+\left(H^{i}\right)^{-\mu}\right)^{-\frac{\gamma}{\mu}}\right]^{-\frac{1}{\gamma}}
$$

is similar to the one used by Acemoglu (2000) or Krusell (2000).

Factor relations in the production process: Referring to the capital-skill complementarity hypothesis, which traces back to Griliches (1969), ${ }^{16}$ authors like Greenwood/Yorukoglu (1997), Krusell(2000) or Goldin/Katz (1998) argue that the complementarity of capital and skills is higher than the complementarity of equipment capital and unskilled labor. From a more historical and long-term perspective, Goldin/Katz (1998) discuss this hypothesis and point out that even at the beginning of the last century capital-skill complementarity may have been as high as in recent periods. ${ }^{17}$ With respect to Information and Communications Technologies (ICTs) Arnal/Ok/Torres (2001, p. 4) conclude that “.... work needs to be reorganized to use ICT effectively; there is a complementarity between highskilled labor on the one hand, and physical capital and new technology on the other.". The overall empirical findings suggest that equipment capital is more complementary to skilled workers than to unskilled workers $[\gamma<\mu]$. The theoretical model has to account for this stylized fact of factor relations. Following Goldin/ Katz (1998) the most simple way to account for this factor relation is to assume a high capital-skill complementarity [ $\mu=1$ (Leontief-technology)], such that

$$
\begin{aligned}
& \mathbf{K}^{i} / H^{i}=\kappa_{H} \equiv \kappa, \\
& \mathbf{K}^{i} / K^{i}=\kappa_{K} \equiv 1 .
\end{aligned}
$$

\footnotetext{
${ }^{16}$ See also the discussion by Hamermesh $(1986,1993)$. After discussing a number of empirical studies Hamermesh summarizes: "Perhaps the most consistent finding is that nonproduction workers (presumable skilled labor) are less easily substituteable for physical capital than are production workers (unskilled labor). .... This supports Rosens' (1968) and Griliches' (1969) results on the capital-skill complementary hypothesis" (Hamermesh (1986) p. 461).

${ }^{17}$ Indirect support comes from Berman/Bound/Griliches (1994), Autor/Katz/Krueger (1998) and Machin/ Van Reenen (1998) who suggests that more computerized industries (capital with embodied IT technologies) have experienced more rapid skill upgrading.
} 
For the relation between capital-skill services and unskilled labor we assume an elasticity of substitution $\mathbf{s}$ between 0 and $1[0<\mathbf{s} \leq 1$, i.e. $0 \leq \gamma<1]$. Thus, we include the Cobb-Douglas case of $\gamma=0$. Using equation (10), aggregate output can be expressed as

$$
\begin{gathered}
X=F\left(N_{u}, N_{s}, h, \lambda\right):=\left[\beta_{\mathrm{L}}\left(\lambda N_{u}\right)^{-\gamma}+\beta_{\mathrm{K}}\left(\kappa h N_{s}\right)^{-\gamma}\right]^{-\frac{1}{\gamma}}, \\
h N_{s}=\kappa^{-1} \boldsymbol{K} .
\end{gathered}
$$

\section{Search and Optimal Vacancies}

A core feature of the matching approach is the introduction of information and transaction costs in labor market activities. A vacancy of kind $j$ offered by firm $i$, $V_{j}^{i}$ is a newly created job or the reoccupation of a presently vacant job offered on the market. The creation of a new job as well as the adjustment for re-filling an existing job absorbs resources. Costs are incurred by offering and filling a vacancy, such as search and selection costs, bureaucracy and administrative costs, training costs as well as all kind of other direct and indirect adjustment costs. The cost to offer a vacancy is measured in units of the final good. Let $c_{V j}$ denote the real value of resources necessary to offer an additional vacancy of type $i$.

In order to maximize the value of the firm, optimal factor inputs as well as optimal vacancies have to be determined. The number of vacancies offered by firm $i, V_{j}^{i}$, is the control variable for adjusting employment. Since firms are small and cannot individually influence the aggregate number of vacancies, $\theta_{j}$ is taken as given for the firm. Since $c_{V j}$ denotes the real value of resources necessary to offer an additional vacancy of type $j$, the reemployment expenditure of firm $i$ in market $j$ equals $c_{V j} V_{j}^{i}$. The present value of profits then is

$$
\pi_{0}^{i}:=\int_{0}^{\infty} e^{-\rho t}\left\{F\left(N_{u}^{i}, \lambda, \mathbf{K}\right)-w_{u} N_{u}^{i}-w_{s} N_{s}^{i}-c_{V u} V_{u}^{i}-c_{V s} V_{s}^{i}-r K^{i}\right\} d t,
$$

where $\rho$ denotes the firm's discount. ${ }^{18}$ Since capital-skill complementarity implies $K=k h N_{s}$, the maximization problem is

$$
\begin{aligned}
& \quad \max _{N_{j} V_{j}} \pi_{0}^{i}:=\int_{0}^{\infty} e^{-\rho t}\left\{F\left(N_{u}^{i}, \lambda, h\right)-w_{u} N_{u}^{i}-\left(w_{s}+r \kappa h\right) N_{s}^{i}-c_{V u} V_{u}^{i}-c_{V u} V_{s}^{i}\right\} d t, \\
& \text { s.t. } \dot{N}_{j}^{i}=V_{u}^{i} q\left(\theta_{j}\right)-\sigma_{j} N_{j}^{i}, \\
& \quad N_{j}^{i}(0)=N_{j, 0}^{i} .
\end{aligned}
$$


From the first order conditions we obtain the conditions for optimal search in the two market segments: ${ }^{19}$

$$
\begin{gathered}
F_{N u}-w_{u}-c_{V u} q\left(\theta_{j}\right)^{-1}\left\lfloor\sigma_{u}+\rho-\dot{c}_{V u} / c_{V u}-v_{u} \dot{\theta}_{u} / \theta_{u}\right\rfloor=0, \\
F_{N s}-\left(w_{u}+r \kappa h\right)-c_{V u} q\left(\theta_{s}\right)^{-1}\left\lfloor\sigma_{u}+\rho-\dot{c}_{V s} / c_{V s}-v_{s} \dot{\theta}_{s} / \theta_{s}\right\rfloor=0 .
\end{gathered}
$$

In these first order conditions $v_{j}$ is used to denote the elasticity of $q\left(\theta_{j}\right)^{-1}$ with respect to $\theta_{j}$. Since $F_{N_{j}^{i}}$ is identical for all firms and the production technology is linear homogenous in physical labor inputs, the conditions can be used to describe individual as well as aggregate search activities. This set of conditions determines the number of vacancies supplied as a function of the workers' marginal productivity, the wage rate (adjusted for capital costs) and the expenditures necessary to maintain or further adjust employment. Throughout this model, we assume that vacancy costs, $c_{V j}$, are a constant fraction of output

$$
c_{V j}=c_{j} X, j=u, s
$$

Since the driving forces of output growth are human capital accumulation and technological progress, equation (14) implies that the cost of offering a vacancy is positively related to these factors.

\section{B. Factor Income and Accumulation}

Determining factor income and accumulation will close the model. We distinguish between two kinds of income: labor or wage income, $Y^{L}$, earned by employed labor, and capital income, $Y^{K}$, earned by interest rates on real capital and profits. Let $r$ be the net user cost of capital, and $\pi$ profits $^{20}$. Labor income and capital income are then defined as

$$
\begin{gathered}
Y^{L} \equiv w_{u} L_{u}+w_{s} N_{s}, \\
Y^{K}=\pi+r K .
\end{gathered}
$$

\footnotetext{
${ }^{18}$ In Appendix 2 we take that in equilibrium the firm's discount rate equals the interest rate $r$.

${ }^{19}$ For details see Appendix $1 \mathrm{~b}$.

${ }^{20}$ As we have a simple wage rule given by (5), firms can have profits.
} 
In our economy two assets are accumulated: human capital, $\mathbf{H}^{21}$, and real capital, $K$. In order to separate domestic human capital investments and domestic or international real capital investments, we assume that human capital, as a human resource, is accumulated from labor income, while real capital is taken from capital income.

If $h$ denotes the average human capital endowment per skilled worker, $\mathbf{H} \equiv h L_{s}$ is the economy's total human capital stock. Total human capital accumulation, $\dot{\mathbf{H}} \equiv \partial \mathbf{H} / \partial t$ is assumed to be a constant fraction $\tau$ of labor income $Y^{L}$ :

$$
\dot{\mathrm{H}} \equiv \dot{h} L_{s}=\tau Y^{L} .
$$

Accumulation of real capital, $\dot{K} \equiv \dot{h} L_{s}=\tau Y^{L}$, is financed out of real capital income with the constant savings rate $s$

$$
\dot{K}=s Y^{K}
$$

In the closed economy all income which is not accumulated in human or real capital will be spent on consuming the domestic final product. In the open economy version, we allow for international factor mobility, i.e. savings are invested in domestic as well as international real capital. If, at the given world interest rate, domestic capital productivity is higher than international interest earnings, the gap between domestic savings and the resulting current account deficit will be financed by international capital inflows $\dot{K}^{F}$. In this case, domestic real capital formation is $\dot{K}=s Y^{K}+\dot{K}^{F}$, and $\dot{K}^{F}>0$.

\section{Closed Economy Steady-state Equilibrium}

The analysis in sections IV to VI will mainly focus on the steady state behavior of the model. The steady state reactions basically reflect the long-run behavior of factor supply and demand. While the level and the structure of physical labor supply are constant over time (eq. (1)), labor efficiency in production increases due to technological progress and human capital accumulation. Therefore, the level and structure of labor supply in efficiency units are determined by the rates of human

\footnotetext{
${ }^{21}$ Please note: $\mathbf{H}=h L_{s}$ is the total human capital accumulated in the economy. As we have unemployment of skilled labor, human capital is not fully used in production. Only the human capital stock of the employed skilled workers $\mathbf{H}=h N_{s}$ is used. Therefore, there is a difference between $\mathbf{H}=h L_{s} \mathrm{H}$ and $H$.
} 
and real capital accumulation, (17) respectively (18), and the rate of technological progress $\hat{\lambda}$. The structure of factor demand depends on the characteristics of the production function (10) and (11), the development of search costs (14), wages (6), and labor market tightness, (3) and (7).

Since in the production process human and real capital are complementary factors, the supply of physical capital places restrictions on the employment opportunities of human capital and vice versa. However, the market for real capital always clears. Therefore, the demand structure is dominated by real capital supply. The human capital endowment of skilled, and thus the rate of human capital accumulation, then determines how many units of skilled workers are necessary to complement the input of real capital.

The demand for unskilled workers is a function of productivity and cost. How the productivity of unskilled labor evolves over time depends on the rate of technological progress and the rate of capital accumulation. The higher the rate of technological progress, the higher the efficiency of unskilled labor, and the lower the demand for physical unskilled labor for any given capital demand. Moreover, the demand for physical unskilled labor will be the higher, the lower the search costs and wages for the unskilled.

The long run equilibrium for real capital as well as for skilled and unskilled workers can be described with three equations. These equations are derived in Appendix 2 and will be denoted the optimal search function for unskilled $\left(\phi_{u}(\ldots)=0\right)$, the optimal search function for skilled $\left(\phi_{s}(\ldots)=0\right)$, and the resource accumulation constraint $(\Phi(\ldots)=0)$.

$$
\begin{aligned}
0 & =1-\frac{1}{1-\omega}\left[\frac{c_{u} \theta_{u}}{\sigma_{u}+p\left(\theta_{u}\right)}\left[\sigma_{u}+r-\hat{\lambda}\right] L_{u}\right]-B_{K}\left[\frac{\tau \varpi}{\hat{\lambda}} \frac{p\left(\theta_{s}\right)}{\sigma_{s}+p\left(\theta_{s}\right)}\right]^{-\gamma} \\
& \equiv \phi_{u}\left(\theta_{u}, \theta_{s}, r, \ldots\right), \phi_{u} \text { curve: search for unskilled labor }
\end{aligned}
$$

Similarly we derive an optimal search function for skilled workers, $\phi_{s}(\ldots)=0$, as ${ }^{22}$

$$
\begin{aligned}
& \begin{array}{l}
0 \\
=\frac{1}{1-\omega}\left[r \kappa \frac{\omega \tau}{\hat{\lambda}} \frac{p\left(\theta_{s}\right)}{\sigma_{s}+p\left(\theta_{s}\right)}+\frac{c_{s} \theta_{s}}{\sigma_{s}+p\left(\theta_{s}\right)}\left[\sigma_{s}+r-\hat{\lambda}\right] L_{s}\right]-\beta_{\mathrm{K}}\left[\frac{\omega \tau}{\hat{\lambda}} \frac{p\left(\theta_{s}\right)}{\sigma_{s}+p\left(\theta_{s}\right)}\right]^{-\gamma} \\
\quad \equiv \phi_{s}\left(\theta_{s}, r, \ldots\right), \phi_{s} \text { curve: search for skilled labor }
\end{array} \\
& \text { with } \frac{\partial \phi_{s}}{\partial \theta_{s}}>0, \frac{\partial \phi_{s}}{\partial r}>0, \frac{\partial \phi_{s}}{\partial L_{s}}>0, \frac{\partial \phi_{s}}{\partial \tau}>0 .
\end{aligned}
$$


The third condition, $\Phi(\ldots)=0$, represents the economy's long-run resource restriction: $:^{23}$

$$
\begin{gathered}
0=\left[1-\omega-\frac{c_{u} \sigma_{u} \theta_{u}}{\sigma_{u}+p\left(\theta_{s}\right)} L_{u}-\frac{c_{u} \sigma_{u} \theta_{u}}{\sigma_{u}+p\left(\theta_{s}\right)} L_{s}\right]-\frac{\tau \kappa}{s} \frac{\omega p\left(\theta_{s}\right)}{\sigma_{s}+p\left(\theta_{s}\right)} \\
\equiv \Phi\left(\theta_{u}, \theta_{s}, \ldots\right), \Phi \text {-curve: long run resource constraint } \\
\text { with } \frac{\partial \Phi}{\partial \theta_{u}}<0, \frac{\partial \Phi}{\partial \theta_{s}}<0, \frac{\partial \Phi}{\partial L_{u}}<0, \frac{\partial \Phi}{\partial L_{s}}<0 .
\end{gathered}
$$

For this system of equations we can apply the implicit function theorem ${ }^{24}$ and establish the existence of a unique solution for the endogenous variables $\theta_{u}, \theta_{s}$, and $\tilde{r}$.

Conditions (19), (20) and (21) are represented graphically in Figure $1 .{ }^{25}$ Equation (21) implies that for any given level of aggregate search activity there also exists an inverse relationship between search activities for different types of workers and thus, an inverse relationship between the employment levels of skilled and unskilled labor. This inverse relationship results from the long run resource constraint of the closed economy - the accumulation constraint for different types of capital. The restriction is binding as long as the economy does not open up to international capital flows. The optimal search conditions (19) and (20) then determine which of the feasible search combinations implied by (21) will result in equilibrium. Figure 1 shows that $\theta_{s}$, and thus the equilibrium unemployment level of the skilled labor, $U_{s}\left(\theta_{s}\right)$, is independent of $\theta_{u}$. The shape of the $\phi_{s}(\ldots)=0$ function therefore reflects that the only factors restricting the employment of the skilled labor are the accumulation rates and technological progress, but not the employment level of unskilled workers. On the contrary, the $\phi_{s}(\ldots)=0$ function has a positive slope. Thus, the demand for unskilled workers will be the higher, the higher the employment level of skilled labor.

\section{Unemployment Effects of International Capital Mobility}

Having derived the equilibrium for the closed economy, we now turn to the open

\footnotetext{
${ }^{22}$ For details see Appendix 3.

${ }^{23}$ For details see Appendix 4.

${ }^{24}$ For details see Appendix 5.

${ }^{25}$ For a discussion of the shape of the graphical representations of (19)-(21) see Appendix 6.
} 
Figure 1. Closed econmy labor market equilibrium

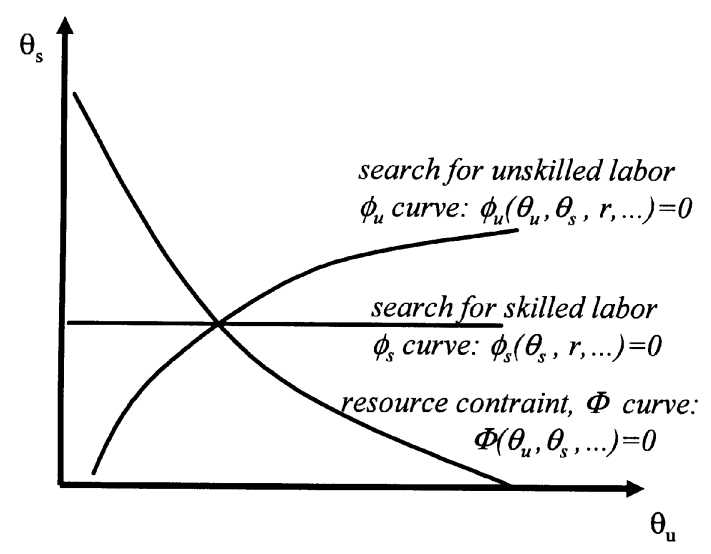

economy version to answer the question: How does capital mobility affect unemployment?

To analyze this question we will assume that in the initial situation the country is relatively low on physical capital, which in turn implies a relatively high real rate of interest $r$ as compared to the world market rate $\bar{r}$. If the country opens up to capital flows the resource constraint represented by the accumulation function (18) no longer binds. Consequently, equation (21) no longer restricts search activities in the labor markets. Only the optimal search conditions (19) and (20) now simultaneously determine the tightness of labor markets $\tilde{\theta}_{u}$ and $\tilde{\theta}_{s}$ for the given world market interest rate $\bar{r} .{ }^{26}$

$$
\begin{aligned}
\phi_{u}\left(\theta_{u}, \theta_{s}, \bar{r}, \ldots\right) & =0, \phi_{u} \text { curve: search for unskilled workers, } \\
\frac{d \theta_{s}}{d \bar{r} \mid \phi_{u}} & =\frac{\partial \phi_{u}^{\prime} d \bar{r}}{\partial \phi_{u}^{\prime} d \theta_{s}}>0 \text { shift of the } \phi_{u} \text {-curve: } \\
\phi_{s}\left(\theta_{u}, \bar{r}, \ldots\right) & =0, \phi_{s} \text { curve: search for skilled labor, } \\
\frac{d \theta_{s}}{d \bar{r} \mid \phi_{u}} & =\frac{\partial \phi_{s}^{\prime} d \bar{r}}{\partial \phi_{s}^{\prime} d \theta_{s}}<0 \text { shift of the } \phi_{u} \text { curve: }
\end{aligned}
$$

Opening for international capital mobility and (in this case) a reduction of domestic interest rates will shift the search function for unskilled workers

\footnotetext{
${ }^{26}$ The system now reduces to two equations solving for the endogenous variables $\theta_{u}$ and $\theta_{s}$. Again we can make use of the implicit function theorem (see Appendix 7) and determine a unique equilibrium for $\tilde{\theta}_{u}$ and $\tilde{\theta}_{s}$. For the reactions see also again Appendix 6 .
} 
Figure 2. Employment effects of international capital inflows

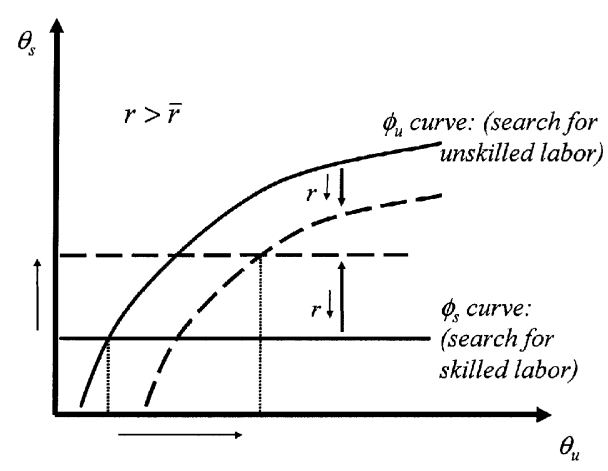

downward and the search function for skilled upward (see Fig. 2). At the new equilibrium labor market tightness $\left(\theta_{u}\right.$ and $\left.\theta_{s}\right)$ will increase. With the change in labor market tightness unemployment rates $\left(v_{u}\right.$ and $\left.v_{s}\right)$ in both segments of the labor market decrease (see (8)).

The economic reactions are straightforward. With a decreasing interest rate, $r>\bar{r}$, inflowing real capital drives up the real capital stock and increases employment opportunities. First, due to the capital skill complementarity additional human capital and skilled workers will be employed. Thus, unemployment in the high skill sector of the labor market decreases. Moreover, an increasing capital stock will increase productivity and the demand for unskilled workers, too. As a second effect, the decreasing interest rate will decrease the opportunity costs for personnel search activities. The real interest rate $^{27}$ is a component of the opportunity cost of firms when investing into search activities instead of real capital. Decreasing opportunity costs translate into higher aggregate search activities for both types of workers and hence will decrease the unemployment rates in both segments of the labor market. Therefore, capital inflows/outflows positively/ negatively affect the unemployment rate in both segments of the labor market. If high unemployment is a major political problem an inflow/outflow of international capital and a decreasing/increasing domestic interest rate will unambiguously generate positive/ negative employment effects in both segments of the labor market.

\section{Unemployment Effects of Labor Mobility: Unskilled labor}

The effects on unemployment of the mobility of unskilled workers are easy to

\footnotetext{
${ }^{27}$ Which in equilibrium is the firms' discount rate $\rho=r$ see also Appendix 2.
} 
derive. Again, optimal search conditions (19) and (20) will determine labor market search equilibrium in both market segments. According to eq. (20) the demand for skilled workers is not affected by an inflow of unskilled workers ${ }^{28}$.

$$
\frac{d \theta_{s}}{d L_{u} \mid \phi_{s}}=0 \text { shift of the } \phi_{s} \text { curve. }
$$

Hence, the $\phi_{s}$ curve will not change its position (see Fig. 3). The $\phi_{u}$ curve on the other hand will shift upward with inflowing unskilled labor. ${ }^{29}$

$$
\frac{d \theta_{u}}{d L_{u} \mid \phi_{u}}>0 \text { shift of the } \phi_{u} \text { curve. }
$$

As a result, labor market tightness will decrease in the market for unskilled workers $\left(\theta_{u} \downarrow\right)$ and hence unemployment increases $\left(v_{u} \uparrow\right)$. Immigration of unskilled workers will increase the unemployment rate for the unskilled. The conclusion thus is that an inflow of unskilled workers will not be matched by a proportionate increase of vacancies for unskilled workers. Skilled workers, however, are not affected by the immigration of unskilled workers. The reason for the neutral effect is the complementarity of real and human capital. Due to the fixed stock of real capital the demand for human capital is constant and independent of the supply of unskilled workers.

Figure 3. Employment effects of migration (unskilled)

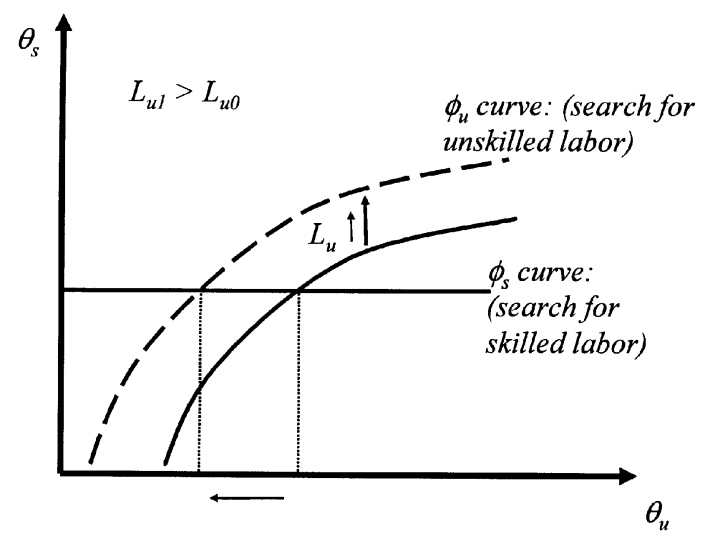

\footnotetext{
${ }^{28}$ See Appendix 3 and 6.

${ }^{29}$ See Appendix 2.
} 


\section{Unemployment Effects of Labor Mobility: Skilled labor}

A rather unexpected unambiguous employment effect is obtained when looking at the migration effects of skilled labor. An inflow of skilled labor will be negative for both unemployment rates. The idea that immigrating skilled labor may generate positive effects for the economy and eventually may help to reduce unemployment is not supported by this approach. After illustrating the mechanics of the model, we will discuss that this effect is well covered by the economic logic of this approach. Therefore, we derive the reactions for the two search functions and obtain: ${ }^{30}$

$$
\begin{aligned}
& \frac{d \theta_{s}}{d L_{s} \mid \phi_{s}}<0 \text { shift of the } \phi_{s} \text { curve and } \\
& \frac{d \theta_{s}}{d L_{s} \mid \phi_{u}}<0 \text { shift of the } \phi_{u} \text { curve. }
\end{aligned}
$$

Since optimal search conditions (19) and (20) determine labor market equilibrium in both market segments Fig. 4 can illustrate the resulting effects. An inflow of skilled labor will shift the $\phi_{s}$ curve downward, while the $\phi_{u}$ curve is not affected. In the new equilibrium both $\theta_{u}$ and $\theta_{s}$, decrease and the unemployment rates in both segments $\left(v_{u}\right.$ and $\left.v_{s}\right)$ increase. Therefore, immigration of skilled workers will affect both segments of the labor market negatively.

The economics are straight forward. An immigration of qualified workers makes skilled workers more available, (un)tightness $\left(\theta_{s} \downarrow\right)$ ) will decrease and the unemployment rate in the skilled labor market segment will increase. Increasing total employment of skilled workers will increase search expenditures for the skilled, too. These expenditures are partly offset by decreasing search expenditures for unskilled, leading to a substitution of skilled against unskilled workers. Hence, the unskilled segment is negatively affected, too. Further, an inflow of skilled labor does not necessarily mean that there is an increasing stock of human capital available in the long run labor market equilibrium. In the long run equilibrium additional skilled labor will be endowed according to the accumulation decision of human capital. Therefore, the pure process of immigration of potentially skilled people will change the domestic human capital stock.

\section{Policy Implications}

The model discussed in the previous sections addresses the effects of

${ }^{30}$ See Appendix 6 
Figure 4. Unemployment effects of an inflow of skilled.

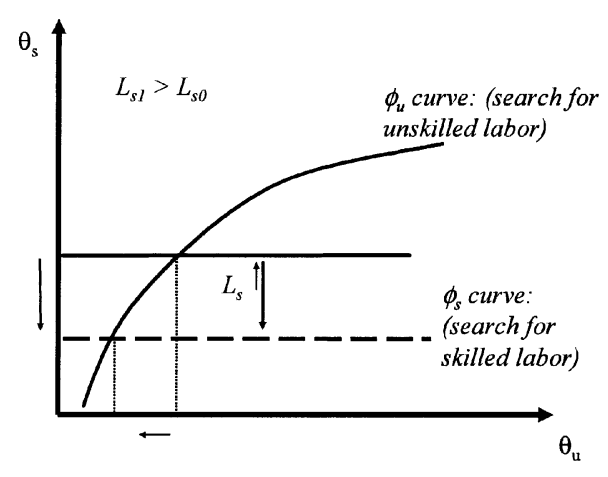

international factor mobility. The production factors considered as mobile are capital and skilled as well as unskilled labor. As a major result, the employment effects of factor mobility were found to be non-symmetric across market segments. Most of the asymmetric effects are related to the search and matching process. They also motivate the major policy implications of the model.

In line with the existing literature, capital mobility is generally improving efficiency due the higher efficiency of capital allocation in internationally liberalized markets. In this paper we focus on unemployment and labor markets. Labor market effects of capital mobility are not symmetric. We find different effects on unemployment for exporting and importing countries. Skilled and unskilled labor will always gain from capital inflows due to an increase in marginal productivity. But for the same reason, they are adversely affected by capital outflows. In addition, the change in capital supply also affects the search behavior of firms. Since interest rates are costs in the firms' investments in recruitment, search activities for both types of workers will increase/decrease if interest rates decrease/increase. According to the model this effect operates in both labor market segments, even if real and human capital are complements and substitute for unskilled labor. As an interesting result we therefore find that inflowing capital does not increase the unemployment rate of the unskilled. Thus, capital importing countries will benefit twice. However, unemployment rates for both, unskilled and skilled labor will increase if the country is a capital exporter. Therefore, capital market liberalization in capital exporting countries should be accompanied by policies to avoid negative employment effects. According to the model such policies must either affect the structure, the level of physical labor or the human capital endowment of skilled workers. For most policies the asymmetry of the 
resulting effects on different labor market segments is the most important problem. The only policy which undoubtedly positively affects both segments of the labor market is an increasing efficiency of the matching process. As a result, for a potentially capital exporting country, capital market integration and liberalization should go along with labor market reforms which improve the matching process. This policy could decrease adverse effects of capital market integration on the unemployment rate. For example, an improved supply and processing of job related information will increase the efficiency of the matching process. A higher search and matching efficiency will then increase the returns on search investments and counteract the negative incentive effect of capital outflows.

Search related external effects are also responsible for asymmetric cross effects of migration and changes in labor supply. In general, immigration of any kind of labor will always adversely affect the own labor market segment. This adverse supply effect is straightforward. In addition, cross effects also exist. The cross effects of immigration are non-symmetrical. Due to a joint effect on search activities, an increasing number of skilled workers also decreases the incentives for firms to search for unskilled workers. This negative cross effect is also present if skilled workers migrate internationally. While the immigration of unskilled workers does not affect the unemployment rate of the skilled, the converse is not true: immigration of skilled workers will have an adverse effect on the unemployment rate in both segments of the labor market. The popular idea that immigrating skilled labor may generate positive effects for the economy and eventually may help to reduce unemployment is not supported by the model. Further, the negative effect on the unemployment rate of unskilled workers can be partially offset by an increase in the rate of educational expenditure $\left[\partial \theta_{u} / \partial \tau>0\right]$. However, policies which simply encourage the immigration of skilled workers will eventually increase the labor market tightness and unemployment for unskilled workers. To attenuate or reverse the adverse labor market effect, a complementary import of physical capital is necessary. Physical capital and skilled workers should be attracted as a bundle.

\section{Summary and Conclusion}

This paper analyzes the employment effects of international factor mobility. The analysis is based on a labor market matching model with skilled and unskilled workers. The production technology is assumed to be a nested CES function. Real capital and human capital - bound to the skilled labor - are complements while the aggregate capital services and unskilled workers are substitutes. Technological 
progress is pure labor augmenting.

The main findings are: 1. Opening up to capital mobility and international capital inflows will generally have positive effects on the firms' job offers. Skilled and unskilled labor will gain from capital inflows: Capital inflows will decrease the interest rate on capital. Since the interest rate on capital is also the opportunity cost for investments in search activities, a lower interest rate will lead to an increase in search efforts in both labor market segments. Higher investments in personnel search activities will increase the probability of filling vacancies, and therefore reduce the unemployment rates. 2. For both, skilled and unskilled workers, labor inflows will adversely affect the own labor market segment: Unskilled/skilled immigration increases labor supply and - given constant investments for search will increase the unemployment rates within these markets, respectively. 3 . The cross labor market effects of immigration are non symmetric: a) The inflow of unskilled workers will not affect the labor market of skilled labor. In equilibrium, skilled workers are immune with respect to the migration of unskilled labor. b) The inflow of skilled labor will negatively affect both unskilled and skilled workers.

Received 9 January 2006, Accepted 17 December 2006

\section{References}

Acemoglu, D. (2000); "Technical Change, Inequality, and the Labor Market", July 2000, pp. 63, National Bureau of Economic Research Working Paper: 7800

Arnal, E. /W. Ok/R. Torres (2001); "Knowledge, Work Organisation and Economic Growth", Labour Market and Social Policy - Occasional Papers No. 50

Autor, D. H./Katz, L. F./Krueger, A. B (1998); "Computing Inequality: Have Computers Changed the Labor Market?”, Quarterly Journal of Economics, November 1998, v. 113, iss. 4, pp. 1169-213.

Baldwin, R./ Venables, A. (1994); "International Migration, Capital Mobility and Transitional Dynamics", Economica, Vol. 61, 285-300.

Berman, E. / Bound, J. / Griliches, Z. (1994); "Changes in the Demand for Skilled Labor within US Manufacturing: Evidence from Annual Survey of Manufactures”, Quarterly Journal of Economics, Vol. 109, No. 2, pp. 367-97.

Borjas, G. J. /Freeman, R.B /Katz, L. (1996); "Searching for the Effect of Immigration on the Labor Market”, American Economic Review, May 1996, v. 86, iss. 2, pp. 246-51.

Blanchard, O. J./ Diamond, P. (1992); "The Flow Approach to Labor Markets", February 1992, pp. 15, National Bureau of Economic Research Working Paper: 4000.

Bound, J./Johnson, G. (1992); "Changes in the Structure of Wages in the 1980s: An Evaluation of Alternative Explanations", American Economic Review, 82(3), 371-92.

Cline, W. (1997); Trade and Income Distribution, Washington DC: Institute for International 
Economics.

Diamond, P. A. / Maskin, E. (1979); “An Equilibrium Analysis of Search and Breach of Contract, I: Steady States”, Bell Journal of Economics, Vol. 10, Spring, pp. 282-316.

Diamond, P. A. (1982); "Wage Determination and Efficiency in Search Equilibrium", Review of Economic Studies, Vol. 49, pp. 217-27.

DiNardo, J. E./Pischke, J.-S. (1997); "The Returns to Computer Use Revisited: Have Pencils Changed the Wage Structure Too?", Quarterly Journal of Economics, February 1997, v. 112, iss. 1, pp. 291-303.

Entorf, H. /Kramarz, F. (1998); "The Impact of New Technologies on Wages: Lessons from Matching Panels on Employees and on Their Firms", Economics of Innovation and New Technology, 1998, v. 5, iss. 2-4, pp. 165-97.

Feenstra, R. C./ Hanson, G. H. (1996); "Globalization, Outsourcing, and Wage Inequality", American Economic Review, May 1996, v. 86, iss. 2, pp. 240-45.

Glass, A. J. / Saggi, K. (1999); "FDI policies under shared factor markets", Journal of International Economics, Vol. 49, pp. 309-332.

Glazer, A./Ranjan P. (2000); "Market Structure, Capital Inflows, and Home Welfare", International Trade Journal, Spring 2000, v. 14, iss. 1, pp. 77-103.

Glazer, A. / Ranjan P. (2003); "Preference Heterogeneity, Wage Inequality, and Trade", Journal of International Economics, August 2003, v. 60, iss. 2, pp. 455-69.

Goldin, C. / Katz, L. F. (1998); "The Origins of Technology-Skill Complementarity", Quarterly Journal of Economics, August 1998, v. 113, iss. 3, pp. 693-732.

Gottschalk, P. / Smeeding, T. (1997); "Cross national comparisons of earnings and income inequality", Journal of Economic Literature, Vol. 35, No. 2, pp. 633-87.

Greenwood, J. / Yorukoglu, M. (1997); “1974”, Carnegie-Rochester Conference Series on Public Policy, June 1997, v. 46, iss. 0, pp. 49-95.

Griliches, Z. (1969) Capital_Skill Complementarity, Review of Economics and Statistics, 51, 465-468.

Hamermesh, D.S. (1986); "The Demand for Labor in the Long Run", Handbook of labor economics. Volumes 1, 1986, pp. 429-71.

Hamermesh, D.S. (1993); "Labor demand", 1993, pp. xvii, 444, Princeton and Chichester, U.K.: Princeton University Press.

Hanson II, J. R. (1995); "Is Cheap Labour a Magnet for Capital?" Journal of Economic Education, pp. 150-156.

Howitt, P. (1985); "Transaction Costs in the Theory of Unemployment", American Economic Review, March 1985, v. 75, iss. 1, pp. 88-100.

Katz, L.F. / Murphy, K.M. (1992); "Changes in Relative Wages, 1963-1987: Supply and Demand Factors", Quarterly Journal of Economics, Vol. 107, No. 428, pp. 35-78.

Koizumi, T. / Kopecky, K. J. (1980); "Foreign Direct Investment, Technology Transfer And Domestic Employment Effects", Journal of International Economics, Vol. 10, pp. 1-20.

Krueger, A. (1993); "How Computers Have Changed the Wage Structure: Evidence from Microdata, 1984-1989”, Quarterly Journal of Economics, February 1993, v. 108, iss. 1, pp. 33-60.

Krugman, P. (2000); “And Now for Something Completely Different: An Alternative Model of Trade, Education, and Inequality", The impact of international trade on wages, 2000, pp. 15-28, NBER Conference Report series. Chicago and London: University of Chicago Press. 
Krusell, P. (2000); "Capital-Skill Complementarity and Inequality: A Macroeconomic Analysis", Econometrica, September 2000, v. 68, iss. 5, pp. 1029-53.

Lall, S. (1995); "Employment and foreign investment: Policy options for developing countries", International Labour Review, pp. 521-540.

Lawrence, R.Z. (1994), Trade, Multinationals, and Labor, NBER Working Paper No. 4836, 1994.

Machin, S. / Van Reenen, J. (1998), "Technology and Changes in Skill Structure: Evidence from Seven OECD Countries”, Quarterly Journal of Economics, November 1998, v. 113, iss. 4, pp. 1215-44.

Michel, P. (1982); "On the Transversality Condition in Infinite Horizon Optimal Problems", Econometrica, Vol. 50, No. 4, pp. 975-85.

Mincer, J. (1991); "Human Capital, Technology, and the Wage Structure: What do Time Series Show?", NRER Working Paper No. 3581, National Bureau of Economic Research, Cambridge.

Mortensen, D. T. (1978); "Specific Capital and Labour Turnover", Bell Journal of Economics, Vol. 9, Autumn, pp. 572-86.

Mortensen, D. T. (1986); "Job Search and Labor Market Analysis", Handbook of labor economics. Volumes 2, 1986, pp. 849-919, Handbooks in Economics series, no. 5 Amsterdam; Oxford and Tokyo: North-Holland; distributed in North America by Elsevier Science, New York.

Mortensen, D. T. (1989); "The Persistence and Indeterminancy of Unemployment in Search Equilibrium", Scandinavian Journal of Economics, 1989, v. 91, iss. 2, pp. 347-70.

Murphy, K. / Topel, R. (1997); "Unemployment and nonemployment", American Economic Review, Vol. 87, No.2, pp. 295-300.

OECD (1996); "The OECD Job Strategy, Vol. II: Analytical Report”, Paris: OECD.

$O E C D$ (1997); "Trade, earnings and employment: assessing the impact of trade with emerging economies on OECD labour markets." Employment Outlook, OECD.

OECD (1998); "The OECD Jobs Strategy, Technology, Productivity and Job Creation, Best Policy Practices”, Paris: OECD.

Petrongolo, B. / Pissarides, C. (2001); "Looking into the Black Box: A Survey of the Matching Function", Journal of Economic Literature, June 2001, v. 39, iss. 2, pp. 390431.

Pissarides, C. (1979); "Job Matchings with State Employment Agencies and Random Search", Economic Journal, Dec. 1979, v. 89, iss. 356, pp. 818-33.

Pissarides, C. (1985); "Short Run Equilibrium Dynamics of Unemployment, Vacancies and Real Wages", American Economic Review, Vol. 75, No. 4, pp. 676-690.

Pissarides, C. (2000); "Equilibrium Unemployment Theory", 2nd ed., Oxford: Basil Blackwell.

Pizer, S. D. (2000), "Does International Competition Undermine Wage Differentials and Increase Inequality?", Journal of International Economics, December 2000, v. 52, iss. 2, pp. 259-82.

Rosen, S. (1968), "Short-Run Employment variation on Class-I Railroads in the United States, 1947-1963", Econometrica, 36, 511-529.

Sachs, J.D / Shatz, H.J. (1996); "U.S. Trade with Developing Countries and Wage Inequality", American Economic Review, May 1996, Vol. 86, Iss. 2, pp. 234-39.

Slauther, M. J. (1995), Multinational Corporations, Outsourcing, and American Wage Divergence, NBER Working Paper, No. 5253, 1995. 
Slaughter, M. / Swagel, P. (1997); "The Effect of Globalization on Wages in the Advanced Economies", IMF Working Papers, WP/97/43.

Stalker, P. (2000); "Workers Without Frontiers: The Impact of Globalization on International Migration", International Labor Organization, 2000.

UNCTAD (2005), Foreign Direct Investment Database, Major FDI Indicators.

Wood, A. (1994); "North-South Trade, Employment and Inequality: Changing Fortunes in a Skill-Driven World", Oxford: Clarendon Press.

Wood, A. (1995); "How trade hurt unskilled workers", Journal of Economic Perspectives, Vol. 9, No. 3, pp. 57-80.

Wood, A. (1997); "Openness and wage inequality in developing countries: the Latin American challenge to East Asian conventional wisdom", World Bank Economic Review, Vol. 11, No.1, pp. 33-57.

Wood, A. (1998); "Globalisation and the Rise in Labour Market Inequalities", Economic Journal, Vol. 108, pp. 1463-1482.

Wood, A. (2002); "Globalization and Wage Inequalities: A Synthesis of Three Theories, Review of World Economics, 2002, Vol. 138, iss. 1, pp. 54-82.

WTO (2005), International Trade Statistics, World merchandise trade by region and selected economies.

\section{Appendix}

\section{Appendix 1a}

Unemployment rate and labor market tightness:

$$
\begin{aligned}
v_{j} & =\frac{U_{j}}{L_{j}} \\
v_{j} & =\frac{U_{j}}{L_{j}}=\frac{V_{j}}{\theta_{j} L_{j}} \frac{N_{j}}{N_{j}} \\
v_{j} & =\frac{N_{j}}{\theta_{j} L_{j}} \frac{V_{j}}{N_{j}}=\frac{N_{j}}{\theta_{j} L_{j}} \frac{\sigma_{j}}{q\left(\theta_{j}\right)} \\
v_{j} & =\frac{\sigma_{j}}{\theta_{j} q\left(\theta_{j}\right)} \frac{N_{j}}{L_{j}}=\frac{\sigma_{j}}{\theta_{j} q\left(\theta_{j}\right)}\left[1-v_{j}\right] \\
v_{j}\left[1+\frac{\sigma_{j}}{\theta_{j} q\left(\theta_{j}\right)}\right] & =\frac{\sigma_{j}}{\theta_{j} q\left(\theta_{j}\right)} \\
v_{j}\left[\frac{\theta_{j} q\left(\theta_{j}\right)}{\left.\sigma_{j}+1\right]}\right] & =1 \\
v_{j} & =\frac{1}{\theta_{j} q\left(\theta_{j}\right)} \\
\sigma_{j}+1 & =\frac{1}{1+\theta_{j} q\left(\theta_{j}\right) / \sigma_{j}} \text { with } \frac{d v_{j}}{d \theta_{j}}<0,
\end{aligned}
$$

due to linear homogenous matching function (2). 


\section{Appendix 1b}

Profits of a representative firm $i$ are

$$
\pi_{0}^{i}:=\int_{0}^{\infty} e^{-\rho t}\left\{F\left(N_{u}^{i}, \lambda, \mathbf{K}\right)-w_{u} N_{u}^{i}-w_{s} N_{s}^{i}-c_{V u} V_{u}^{i}-c_{V s} V_{s}^{i}-r K^{i}\right\} d t,
$$

where $\rho$ denotes the firm's discount rate. Since profit maximization implies $K=k h N_{s}$ the maximization problem is

$$
\begin{aligned}
\max _{N_{j}, V_{j}} \pi_{0}^{i} & :=\int_{0}^{\infty} e^{-\rho t}\left\{F\left(N_{u}^{i}, N_{s}^{i}, \lambda, h\right)-w_{u} N_{u}^{i}-\left(w_{s}+r k h\right) N_{s}^{i}-c_{V u} V_{u}^{i}-c_{V s} V_{s}^{i}\right\} d t, \\
\text { s.t. } \quad \dot{N}_{j}^{i} & =V_{u}^{i} q\left(\theta_{j}\right)-\sigma_{j} N_{j}^{i}, \\
N_{j}^{i}(0) & =N_{j, 0}^{i},
\end{aligned}
$$

for $j=u, s$. This problem can be solved by setting up the present-value Hamiltonian function $\mathrm{H}\left(N_{u}^{i}, N_{s}^{i}, V_{u}^{i}, V_{s}^{i}, \mu_{u}, \mu_{s}, t\right)$ with $\mu_{j}$ as the costate variables. In addition, let $F_{N j}$ denote the partial derivative of $F(\cdot)$ with respect to $N_{j}$. Then, the Hamiltonian conditions are

$$
\begin{array}{r}
0=\frac{\partial \mathrm{H}}{\partial V_{j}^{i}} \Leftrightarrow \quad 0=-e^{-\rho t} c_{V j}+\mu_{j} q\left(\theta_{j}\right), \quad j=u, s ; \\
-\dot{\mu}_{u}=\frac{\partial \mathrm{H}}{\partial N_{u}^{i}} \Leftrightarrow \quad-\dot{\mu}_{u}=e^{-\rho t}\left[F_{N_{u}^{i}}-w_{u}\right]-\mu_{u} \sigma_{u}, \\
-\dot{\mu}_{s}=\frac{\partial \mathrm{H}}{\partial N_{s}^{i}} \Leftrightarrow \quad-\dot{\mu}_{s}=e^{-\rho t}\left[F_{N_{s}^{i}}-w_{s}-r s h\right]-\mu_{s} \sigma_{s}, \\
\dot{N}_{j}^{i}=\frac{\partial \mathrm{H}}{\partial \mu_{j}} \Leftrightarrow \quad \dot{N}_{j}^{i}=V_{j}^{i} q\left(\theta_{j}\right)-\sigma_{j} N_{j}^{i}, \quad j=u, s .
\end{array}
$$

and the transversality condition is ${ }^{32}$

$$
\lim _{t \rightarrow \infty} \mathrm{H}(t)=0 .
$$

If (22a) is differentiated with respect to time and the result is substituted for $\dot{\mu}_{j}$ in (22b) and (22c), respectively, we arrive at

$$
\begin{gathered}
F_{N u}-w_{u}-c_{V u} q\left(\theta_{u}\right)^{-1}\left[\sigma_{u}+\rho-\dot{c}_{V u} / c_{V u}-v_{u} \dot{\theta}_{u} / \theta_{u}\right]=0, \\
F_{N s}-\left(w_{s}+r k h\right)-c_{V s} q\left(\theta_{s}\right)^{-1}\left[\sigma_{s}+\rho-\dot{c}_{V s} / c_{V s}-v_{s} \dot{\theta}_{s} / \theta_{s}\right]=0 .
\end{gathered}
$$




\section{Appendix 2}

\section{Derivation of the functions}

The $f o c$ for $N_{u}$, equation (13a), is equivalent to $\phi_{u}\left(\theta_{u}, \theta_{s}, r, \ldots\right)=0$

$$
\begin{aligned}
0 & =1-\frac{1}{1-\omega}\left[\frac{c_{u} \theta_{u}}{\sigma_{u}+p\left(\theta_{u}\right)}\left[\sigma_{u}+r-\hat{\lambda}\right] L_{u}\right]-\beta_{\mathrm{K}}\left[\frac{\tau \omega}{\hat{\lambda}} \frac{p\left(\theta_{s}\right)}{\sigma_{s}+p\left(\theta_{s}\right)}\right]^{-\gamma} \\
& \equiv \phi_{u}\left(\theta_{u}, \theta_{s}, r, \ldots\right) .
\end{aligned}
$$

To derive this equation we use the fact that by definition:

$$
\begin{gathered}
S_{N_{j}}:=\frac{F_{N_{j}} N_{j}}{X}, \\
S_{N u}=1-S_{N_{s}},
\end{gathered}
$$

and

$$
c_{j}=c_{V j} / X
$$

For steady state we can also apply the conditions

$$
\begin{gathered}
\dot{\theta}_{u} / \theta_{u}=0, \\
\frac{\dot{c}_{V u}}{c_{V u}}=\frac{\dot{X}}{X}=\hat{\lambda}, \\
\rho=r .
\end{gathered}
$$

Moreover, according to the production function (11) the factor share of skilled labor is

$$
S_{N s}=\beta_{\mathbf{K}}\left(h N_{s} / X\right)^{-\gamma}
$$

and

$$
\hat{h}=\hat{\lambda} \Leftrightarrow \frac{h N_{s}}{X}=\frac{\tau \omega}{\hat{\lambda}} \frac{p\left(\theta_{s}\right)}{\sigma_{s}+p\left(\theta_{s}\right)} .
$$

Partial Derivatives of the implicit function $0=\phi\left(\theta_{w}, \theta_{s}, r, \ldots\right)$

Let

$$
\begin{aligned}
& G_{j}\left(\theta_{j}\right) \equiv \frac{c_{j} \theta_{j}}{\sigma_{j}+p\left(\theta_{j}\right)}, \text { with } \frac{\partial G_{j}}{\partial \theta_{j}}>0, \\
& Q_{j}\left(\theta_{j}\right) \equiv \frac{p\left(\theta_{j}\right)}{\sigma_{j}+p\left(\theta_{j}\right)}, \text { with } \frac{\partial Q_{j}}{\partial \theta_{j}}>0 .
\end{aligned}
$$

${ }^{32}$ See Michel (1982) for a discussion of this type of transversality condition in infinite horizon control problems. 
The partials of the function can then be expressed as

$$
\begin{aligned}
& \frac{\partial \phi_{u}}{\partial \theta_{u}}=-\frac{\sigma_{u}+r-\hat{\lambda}}{1-\omega} L_{u} \frac{\partial G_{u}}{\partial \theta_{u}}<0 \\
& \frac{\partial \phi_{u}}{\partial \theta_{s}}=\beta \kappa \gamma\left[\frac{\tau \omega}{\hat{\lambda}} Q_{s}\left(\theta_{s}\right)\right]^{-(1+\gamma)} \frac{\tau \omega}{\hat{\lambda}} \frac{\partial Q_{s}}{\partial \theta_{s}} \geq 0 \\
& \frac{\partial \phi_{u}}{\partial r}=-\frac{G_{u}\left(\theta_{u}\right)}{1-\omega}<0 \\
& \frac{\partial \phi_{u}}{\partial L_{u}}=-\frac{G_{u}\left(\theta_{u}\right)}{1-\omega}\left[\sigma_{u}+r-\hat{\lambda}\right]<0 \\
& \frac{\partial \phi_{u}}{\partial L_{s}}=0 \\
& \frac{\partial \phi_{u}}{\partial \tau}=\gamma \beta \kappa\left[\frac{\tau \omega}{\hat{\lambda}} \frac{p\left(\theta_{s}\right)}{\sigma_{s}+p\left(\theta_{s}\right)}\right]^{-(\gamma+1)} \frac{\omega}{\hat{\lambda}} Q_{s}\left(\theta_{s}\right)>0
\end{aligned}
$$

\section{Appendix 3}

Derivation of the functions $\phi_{s}\left(\theta_{u}, \theta_{s}, r, \ldots\right)=0$

The $f o c$ for $N_{s}$, equation (13b), can be expressed as

$$
\begin{aligned}
0 & =\frac{1}{1-\omega}\left[r \kappa \frac{\tau \omega}{\hat{\lambda}} \frac{p\left(\theta_{s}\right)}{\sigma_{s}+p\left(\theta_{s}\right)}+\frac{c_{s} \theta_{s}}{\sigma_{s}+p\left(\theta_{s}\right)}\left[\sigma_{s}+r-\hat{\lambda}\right] L_{s}\right]-\beta_{\kappa}\left[\frac{\tau \omega}{\hat{\lambda}} \frac{p\left(\theta_{s}\right)}{\sigma_{s}+p\left(\theta_{s}\right)}\right]^{-\gamma} \\
& \equiv \phi_{s}\left(\theta_{s}, r, \ldots\right),
\end{aligned}
$$

once the results in Appendix 2 with respect to $N_{u}$ and the fact that $S_{N u}=1-S_{N s}$ are taken into account.

\section{Partial Derivatives of the implicit function}

The partials of the $\phi_{u}$ function can then be expressed as

$$
\begin{aligned}
& \frac{\partial \phi_{s}}{\partial \theta_{u}}=0 \\
& \frac{\partial \phi_{s}}{\partial \theta_{s}}=\frac{1}{1-\omega}\left[r \kappa \frac{\omega \tau}{\hat{\lambda}} \frac{\partial Q_{s}}{\partial \theta_{s}}+\left[\sigma_{s}+r-\hat{\lambda}\right] L_{s} \frac{\partial G_{s}}{\partial \theta_{s}}\right]+\beta \kappa \gamma\left[\frac{\tau \omega}{\hat{\lambda}} Q_{s}\left(\theta_{s}\right)\right]^{-(1+\gamma)} \frac{\tau \omega}{\hat{\lambda}} \frac{\partial Q_{s}}{\partial \theta_{s}}>0 \\
& \frac{\partial \phi_{s}}{\partial r}=\frac{1}{1-\omega}\left[r \kappa \frac{\omega \tau}{\hat{\lambda}} Q_{s}\left(\theta_{s}\right)+G_{s}\left(\theta_{s}\right) L_{s}\right]>0
\end{aligned}
$$




$$
\begin{aligned}
& \frac{\partial \phi_{s}}{\partial L_{u}}=0 \\
& \frac{\partial \phi_{u}}{\partial L_{s}}=\frac{G_{s}\left(\theta_{s}\right)}{1-\omega}\left[\sigma_{s}+r-\hat{\lambda}\right]>0 \\
& \frac{\partial \phi_{s}}{\partial \tau}=\left[\frac{r \kappa}{1-\omega}+\gamma \beta \kappa\left[\frac{\tau \omega}{\hat{\lambda}} Q_{s}\left(\theta_{s}\right)\right]^{-(\gamma+1)}\right] \frac{\omega}{\hat{\lambda}} Q_{s}\left(\theta_{s}\right)>0
\end{aligned}
$$

\section{Appendix 4}

\section{Derivation of equation (21)}

Given (18) and (17), in any steady state the following condition must hold:

$$
\frac{\dot{H}}{H}=\frac{\dot{K}}{K} \Leftrightarrow s \frac{Y^{K}}{K}=\tau \frac{Y^{L}}{h L_{s}}
$$

The growth rate of aggregate human capital is

with

$$
\frac{\dot{H}}{H}=\tau\left[w_{u} N_{u}+w_{s} N_{s}\right]
$$

$$
w_{u} N_{u}+w_{s} N_{s}=\omega\left[F_{u} N_{u}+F_{s} N_{s}\right]=\omega X
$$

Moreover, $w_{u}$ and $w_{s}$ are given by (6), and capital income equals

$$
\begin{aligned}
Y^{K} & =X-Y^{L}-c_{u} X V_{u}-c_{s} X V_{s} \\
& =\left[(1-\omega)-\left[\frac{c_{u} \sigma_{u} \theta_{u}}{\sigma_{u}+p\left(\theta_{u}\right)} L_{u}+\frac{c_{s} \sigma_{s} \theta_{s}}{\sigma_{s}+p\left(\theta_{s}\right)} L_{s}\right]\right] X .
\end{aligned}
$$

Thus, we have

$$
s \frac{Y^{K}}{K}=\tau \frac{Y^{L}}{h L_{s}} \Leftrightarrow\left[(1-\omega)-\frac{c_{u} \sigma_{u} \theta_{u}}{\sigma_{u}+p\left(\theta_{u}\right)}-\frac{c_{s} \sigma_{s} \theta_{s}}{\sigma_{s}+p\left(\theta_{s}\right)} L_{s}\right]=\frac{\tau \omega}{s \kappa} \frac{p\left(\theta_{s}\right)}{\sigma_{s}+p\left(\theta_{s}\right)}
$$

Then, a function $\Phi\left(\theta_{u}, \theta_{s}, \ldots\right)$ can be defined as

$$
0=\left[1-\omega-\frac{c_{u} \sigma_{u} \theta_{u}}{\sigma_{u}+p\left(\theta_{u}\right)} L_{u}-\frac{c_{s} \sigma_{s} \theta_{s}}{\sigma_{s}+p\left(\theta_{s}\right)} L_{s}\right]-\frac{\tau \kappa \omega}{s} \frac{p\left(\theta_{s}\right)}{\sigma_{s}+p\left(\theta_{s}\right)} \equiv \Phi\left(\theta_{u}, \theta_{s}, \ldots\right)
$$

\section{Partial derivative of $\Phi(\ldots)=0$}

Once $\theta_{u} q\left(\theta_{u}\right)=p\left(\theta_{u}\right)$ is taken into account, the partials of $\Phi\left(\theta_{u}, \theta_{s}, \ldots\right)=0$ can be evaluated using 


$$
\begin{aligned}
\frac{\partial \Phi}{\partial \theta_{u}} & =-\frac{\partial}{\partial \theta_{u}} \frac{c_{u} \sigma_{u} \theta_{u}}{\sigma_{u}+\theta_{u} q\left(\theta_{u}\right)} L_{u} \\
& =-\frac{c_{u} \sigma_{u}^{2}-c_{u} \sigma_{u} \theta_{u} d q\left(\theta_{u}\right) / d \theta_{u}}{\left[\sigma_{u}+\theta_{u} q\left(\theta_{u}\right)\right]^{2}} L_{u}<0,
\end{aligned}
$$

and

$$
\begin{aligned}
\frac{\partial \Phi}{\partial \theta_{s}} & =-\frac{\partial}{\partial \theta_{s}} \frac{c_{s} \sigma_{s} \theta_{s}}{\sigma_{s}+\theta_{s} q\left(\theta_{s}\right)} L_{s}-\frac{\tau \kappa \omega}{s} \frac{\partial}{\partial \theta_{s}} \frac{p\left(\theta_{s}\right)}{\sigma_{s}+p\left(\theta_{s}\right)} \\
& =-\frac{\partial}{\partial \theta_{s}} \frac{c_{s} \sigma_{s} \theta_{s}}{\sigma_{s}+\theta_{s} q\left(\theta_{s}\right)} L_{s}-\frac{\tau \kappa \omega}{s} \frac{\partial}{\partial \theta_{s}} \frac{\tilde{N}\left(\theta_{s}\right)}{L_{s}}<0,
\end{aligned}
$$

The partials of $\Phi=0$ are

$$
\begin{aligned}
& \frac{\partial \Phi}{\partial \theta_{u}}=-L_{u} \sigma_{u} \frac{\partial G_{u}}{\partial \theta_{u}}<0 \\
& \frac{\partial \Phi}{\partial \theta_{s}}=-L_{s} \sigma_{s} \frac{\partial G_{s}}{\partial \theta_{s}}-\frac{\tau \kappa \omega}{s} \frac{\partial Q_{s}}{\partial \theta_{s}}<0 \\
& \frac{\partial \Phi}{\partial r}=0
\end{aligned}
$$

\section{Appendix 5}

For $\gamma \geq 0$ the determinant of the Jacobian matrix of the system of equations (19), (20) and (27) is characterized by

$$
|J|=\left|\begin{array}{c}
-+- \\
0++ \\
--0
\end{array}\right|<0
$$

Since $|J|<0$ we can apply the implicit function theorem to establish a unique solution for the endogenous variables $\tilde{\theta}_{u}, \tilde{\theta}_{u}$ and $\tilde{r}$.

\section{Appendix 6}

The shape of the $\phi_{u}$ curve in the $\phi_{s}-\phi_{u}$ plane

Applying the implicit function theorem for the function $0=\phi_{u}\left(\theta_{u}, \theta_{s}, r, L_{u}, L_{s}\right)$ [see Appendix 5] and making use of Appendix 2 we have

$$
\left.\frac{d \theta_{s}}{d \theta_{u} \mid}\right|_{\phi_{u}}=-\frac{\partial \phi_{u} / \partial \theta_{u}}{\partial \phi_{u} / \partial \theta_{s}}>0, \frac{d \theta_{s}}{d L_{u}}\left|\phi_{u}=-\frac{\partial \phi_{u} / \partial L_{u}}{\partial \phi_{u} / \partial \theta_{s}}<0, \frac{d \theta_{s}}{d L_{u}}\right|_{\phi_{u}}=-\frac{\partial \phi_{u} / \partial L_{s}}{\partial \phi_{u} / \partial \theta_{s}}=0,
$$




$$
\frac{d \theta_{s}}{d r}\left|\phi_{u}=-\frac{\partial \phi_{u} / \partial r}{\partial \phi_{u} / \partial \theta_{s}}>0, \frac{d \theta_{s}}{d \tau}\right| \phi_{u}=-\frac{\partial \phi_{u} / \partial \tau}{\partial \phi_{u} / \partial \theta_{s}}<0
$$

The shape of the $\phi_{s}$ curve in the $\theta_{s}-\theta_{u}$ plane

Applying the implicit function theorem for the function $0=\phi_{s}\left(\theta_{u}, \theta_{s}, r, L_{u}, L_{s}\right)$ [see Appendix 5] and making use of Appendix 3 we have

$$
\begin{array}{r}
\left.\frac{d \theta_{s}}{d \theta_{u}}\right|_{\phi_{s}=-\frac{\partial \phi_{s} / \partial \theta_{u}}{\partial \phi_{s} / \partial \theta_{s}}=0, \frac{d \theta_{s}}{d L_{u}} \mid \phi_{u}}=-\frac{\partial \phi_{s} / \partial L_{u}}{\partial \phi_{s} / \partial \theta_{s}}=0,\left.\frac{d \theta_{s}}{d L_{s}}\right|_{\phi_{s}}=-\frac{\partial \phi_{s} / \partial L_{s}}{\partial \phi_{s} / \partial \theta_{s}}<0, \\
\left.\frac{d \theta_{s}}{d r}\right|_{\phi_{s}}=-\frac{\partial \phi_{s} / \partial r}{\partial \phi_{s} / \partial \theta_{s}}<0,\left.\frac{d \theta_{s}}{d \tau}\right|_{\phi_{s}}=-\frac{\partial \phi_{s} / \partial \tau}{\partial \phi_{s} / \partial \theta_{s}}<0,
\end{array}
$$

The shape of $\Phi$-curve in the $\theta_{s}-\theta_{u}$ plane

Applying the implicit function theorem for $0=\Phi\left(\theta_{u}, \theta_{s}, L_{u}, L_{s}\right)$ we have

$$
\left.\frac{d \theta_{s}}{d \theta_{u}}\right|_{\Phi}=-\frac{-\partial \Phi / \partial \theta_{u}}{\partial \Phi / \partial \theta_{s}}<0
$$

\section{Appendix 7}

For $\gamma \geq 0$ the determinant of the Jacobian matrix of the system of equations (19) and (20) is characterized by

$$
|J|=\left|\begin{array}{c}
-+ \\
0+
\end{array}\right|<0
$$

Since $|J|<0$ we can apply the implicit function theorem to establish a unique solution for the endogenous variables $\tilde{\theta}_{u}$ and $\tilde{\theta}_{u}$. 